\title{
Worldwide 1-month case fatality of ischaemic stroke and the temporal trend
}

To cite: Zhang $\mathrm{R}$, Wang $\mathrm{Y}$, Fang J, et al. Worldwide 1 -month case fatality of ischaemic stroke and the temporal trend. Stroke \& Vascular Neurology 2020;5: e000371. doi:10.1136/svn2020-000371

- Additional material is published online only. To view please visit the journal online (http://dx.doi.org/10.1136/svn2020-000371).

Received 4 March 2020 Revised 1 June 2020 Accepted 2 June 2020 Published Online First 13 July 2020

\section{Check for updates}

(c) Author(s) (or their employer(s)) 2020. Re-use permitted under CC BY-NC. No commercial re-use. See rights and permissions. Published by BMJ.

${ }^{1}$ Department of Neurology, Beijing Tiantan Hospital, Capital Medical University, Beijing,

China

${ }^{2}$ China National Clinical

Research Center for

Neurological Diseases, Beijing, China

${ }^{3}$ ICES, Toronto, Ontario, Canada

Correspondence to

Dr Gaifen Liu;

liugaifen1997@163.com

\author{
Runhua Zhang (D) , ${ }^{1,2}$ Yu Wang, ${ }^{1}$ Jiming Fang, ${ }^{3}$ Miaoxin Yu, ${ }^{1}$ Yongjun Wang (D) , ${ }^{1,2}$ \\ Gaifen Liu (D) 1,2
}

\section{ABSTRACT}

Background The 1-month case fatality of ischaemic stroke is an essential epidemiological metric. Whereas the case fatality after ischaemic stroke and the temporal trend is uncertain. We aimed to estimate the 1-month case fatality of ischaemic stroke and its temporal trend, as well as its regional variation.

Methods We searched PubMed and Embase to identify the studies for 1-month case fatality of ischaemic stroke . The population-based studies were included. Two investigators extracted the data and assessed the quality independently. One-month case fatality of ischaemic stroke was estimated using a random effects model. The temporal trend was evaluated using a mixed-effect meta-regression model.

Results A total of 59 articles with 77 time periods were included. The worldwide 1-month case fatality of ischaemic stroke was $13.5 \%$ (95\% $\mathrm{Cl} 12.3 \%$ to $14.7 \%)$. The case fatality was $10.8 \%$ (95\% Cl $8.3 \%$ to $13.5 \%$ ) in Asia, $14.2 \%$ (95\% Cl $12.6 \%$ to $15.9 \%)$ in Europe, $14.0 \%$ (95\% Cl 11.2\% to $17.1 \%$ ) in South America and Caribbean, $14.0 \%$ (95\% Cl $9.5 \%$ to $19.1 \%)$ in North America and $12.5 \%(95 \% \mathrm{Cl}$ $11.1 \%$ to $13.9 \%$ ) in Australia and New Zealand. Overall, there was a non-significant decrease of $0.1 \%$ per year in case fatality. It decreased significantly in Europe $(-0.2 \%$ annually, $95 \% \mathrm{Cl}-0.4 \%$ to $-0.01 \%$ ) and North America $(-0.2 \%$ annually, $95 \% \mathrm{Cl}-0.4 \%$ to $-0.04 \%)$, increased significantly in Australia and New Zealand $(0.2 \%$ annually, $95 \% \mathrm{Cl} 0.1 \%$ to $0.4 \%$ ), while no evidence of change in other regions.

Conclusion The 1-month case fatality of ischaemic stroke and its temporal trend were divergent across regions. Further studies are needed to address the reason of the regional difference, which will be helpful to guide the effort of reducing stroke burden.

In the past three decades, much progress has been made in the diagnosis and treatment of stroke. ${ }^{1}$ Some prognostic scales are proposed to predict the short-term or long-term case fatality after stroke. ${ }^{2}$ Early intervention on patients identified with a high risk of mortality may increase the survival rate. It is suggested that a stroke patient cared in a stroke unit had a lower rate of mortality because of organised care. ${ }^{3}$ Moreover, new neuroimaging technologies, intravenous thrombolysis and intraarterial therapy are introduced to improve the outcome of stroke. ${ }^{4}$ According to the Global Burden of Disease 2015, the age-standardised mortality rate of stroke decreased by $21 \%$ since $2005 .{ }^{5}$ Moreover, the disability-adjusted life years of stroke reduced from 2430.8 in 1990 to 1806.9 in $2013 .{ }^{6}$ The reduction may be associated with lower incidence and case fatality. However, whether the case fatality of stroke has decreased remains uncertain. A systematic review with 44 time periods found that the case fatality of intracerebral haemorrhage did not decrease significantly from 1980 to $2008 .^{7}$ By contrast, the 1 -month case fatality of aneurysmal subarachnoid haemorrhage decreased by $0.6 \%$ per year from 1973 to 2002. ${ }^{1}$ Although numerous studies have reported the case fatality of ischaemic stroke, the data of case fatality after ischaemic stroke was conflicting and few studies have investigated the temporal trend.

We aimed to estimate the 1-month case fatality of ischaemic stroke based on all available population-based studies and explore the temporal trend of the case fatality after ischaemic stroke, as well as its regional variation.

\section{METHODS}

The meta-analysis was performed according to the Meta-analyses of Observational Studies in Epidemiology guidelines (MOOSE). The authors declare that all of the data used in this systematic review and meta-analysis are available within the article and in the online supplementary data.

\section{Search strategy}

We searched PubMed and Embase to identify the studies published between 1 January 1980 and 31 December 2018. A search strategy was developed in a combination of words in title and abstract, Medical Subject Headings for patients for each database. We used search terms relating to stroke (eg, 'ischemic stroke', 'cerebrovascular disease' or 'brain infarct') and mortality (eg, 'fatality', 'death') and 30-day or 28-day (eg, 'thirty-day', 'one month' or 'twenty-eight') and population (eg, 'population', 'community' or 'registry') for studies reported case fatality of ischaemic stroke. 
Additionally, we searched relevant reference lists of retrieved studies by hand.

\section{Study identification and selection criteria}

Two investigators independently conducted screening of titles and abstracts. Related studies were reviewed in full-text to identify qualification. The discrepancy was resolved after discussing it with the third reviewer.

We included population-based studies that reported the 1-month case fatality of ischeamic stroke. The criteria for inclusion were that: (1) they reported 30-day or 28-day case fatality of ischeamic stroke and (2) the study was population-based.

We excluded the studies if (1) all included stroke patients were accompanied with specified diseases such as myocardial infarction, atrial fibrillation, heart failure or diabetes; (2) the rates of 1-month case fatality were grouped with haemorrhagic stroke and transient ischaemic attack (TIA) and not available separately for ischeamic stroke; (3) it was a case-control study or randomised clinical trial or abstract or systematic review or opinion; (4) the patients were identified by International Classification of Diseases code from the administrative database; (5) the lower age limit was greater than 39 years; and (6) the upper age limit was lower than 74 years.

If the studies had the sources from the same cohort or population in the same study period, we kept the one with the largest number of patients. When the 1-month case fatality of ischaemic stroke was reported by year, we included different 1-month case fatalities from different periods as separated ones. If the case fatality of ischaemic stroke was reported with other types of stroke, we would contact the corresponding author through email for clarification of the data. If we could not obtain the data from the author, the study would be excluded.

\section{Data extraction}

For each eligible study, the following information was extracted if provided: first author's name, publication year, country, cohort name, study period, mean age of patients, sample size, number of death and 1-month case fatality.

One-month case fatality was defined as the percentage of patients with ischaemic stroke who died within 1 month. If possible, we recalculated the 1-month case fatality of ischaemic stroke without other types of stroke (eg, TIA or intracerebral haemorrhage).

\section{Quality assessment}

We assessed the quality of the individual study with reference to the Newcastle-Ottawa Scale. ${ }^{8}$ The items in our quality assessment were the following: representativeness of the ischaemic stroke in the community, the rate of brain imaging, sample size, the method of case finding, whether there were reported mean age of the population and the proportion of gender (online supplementary table 1).

\section{Statistical analysis}

For each study, the 1-month case fatality was calculated from the raw number of patients and populations, and the corresponding 95\% CI was derived. Concerning the distribution of case fatality, we used arcsine transformations which were optimal for dealing with binary data with low rates. We evaluated the heterogeneity between studies with $I^{2}$ statistic which represents the percentage of total variation due to heterogeneity between studies rather than chance. Values of 25\%, 50\% and $75 \%$ signify low, middle and high heterogeneity, respectively. If the between-study heterogeneity was high, we would use random effects models to pool the case fatalities. Otherwise, we would use the fixed effect model. We grouped the studies by geographical region and summarised the 1-month case fatality of ischaemic stroke separated by North America, South America and Caribbean, Europe, Australia and New Zealand and Asia. We used the metaregression to compare the difference between regions, and we used the region of the lowest case fatality (Asia) as the reference to calculate the risk ratio (RR). Also, we adjusted the midyear of the study in the meta-regression model to remove the effect of temporal trends. Genderspecific and age-specific case fatality was calculated if the corresponding case fatality rate of gender and age was available.

We used the mixed effect meta-regression model to assess the worldwide temporal trend of case fatality of ischaemic stroke. The result was reported as the percentage change of 1-month case fatality per calendar year. To explore the divergent trends across continents or countries, we estimated separately the temporal trends in different regions by using linear regression.

When testing the sensitivity of the results, we did the following analysis. First, we excluded the studies in which the patients were not the first-ever stroke, to adjust for the influence of first-ever and recurrent stroke. Second, concerning the false diagnosis of ischaemic stroke, only the study in which the brain imaging rate was higher than $80 \%$ was included to recalculate the case fatality. We used the Egger test to examine the potential publication bias and adjusted the estimation by using the method of trimand-fill when appropriate.

All analyses were conducted with R software (V.3.5.1) and SAS (V.9.4, SAS Institute Inc, Cary, North Carolina). All tests were two-sided and a $\mathrm{p}$ value less than 0.05 was considered statistically significant.

\section{RESULTS}

\section{Selection process and study characteristics}

A total of 2678 studies were independently screened through titles and abstracts by two reviewers (RZ and YW). Thereafter, 335 potential related full-texts were assessed. Finally, 59 articles with 77 time periods were included in the meta-analysis (figure 1 ).

The systematic review and meta-analysis consisted of 58301 patients with ischaemic stroke and 7558 deaths 


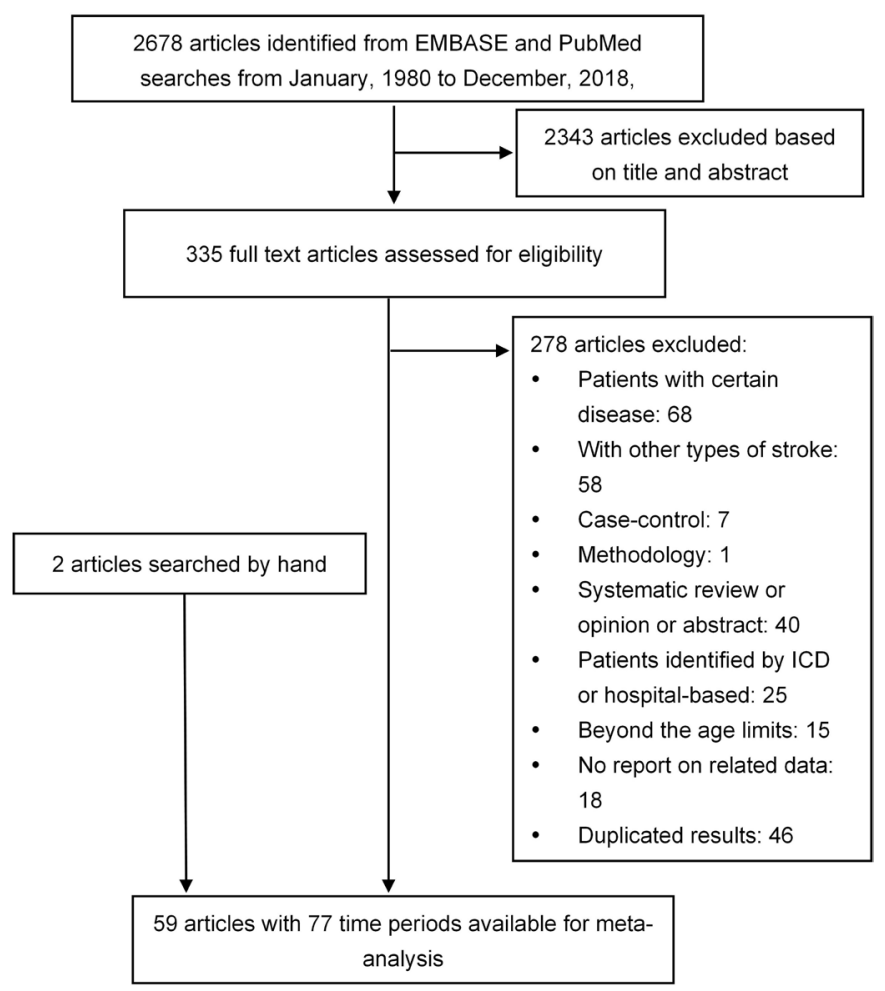

Figure 1 Flow chart of the study selection. ICD, International Classification of Diseases.

within a month. The study was based on population-based case fatality data from Europe (43 time periods), Asia (11 time periods), North America (seven time periods), South America and Caribbean (eight time periods) and Australia and New Zealand (eight time periods) (table 1). Online supplementary table 2 summarised the characteristics of the included study periods. The mid-years of study periods were between 1955 and 2016, spanning over six decades. A total of $64(83 \%)$ study periods were comprised of patients with first-ever ischaemic stroke. There were $56(73 \%)$ study periods with more than $80 \%$ patients who underwent brain CT or MRI or autopsy. The sample sizes ranged from 57 to 9074 . The average age of the ischaemic stroke patients was 71.6 (data were from 59 study periods with 40371 patients) and the average age of ischaemic stroke was lower in Saudi Arabia, Asia (57.8 years) and higher in Perth, Australia (79 years).

\section{One-month case fatality of ischaemic stroke}

The 1-month case fatalities from identified study periods varied from $5 \%$ to $37.6 \%$. The case fatality of each study period is listed in figures 2 and 3. Overall, the polled 1-month case fatality in patients with ischaemic stroke was $13.5 \%$ (95\% CI $12.3 \%$ to $14.7 \%$ ).

When we re-estimated the case fatality according to geographical region, and the 1-month case fatality in the different regions varied (figures 2 and 3 ). The case fatality was $10.8 \%$ (95\% CI $8.3 \%$ to $13.5 \%$ ) in Asia, $14.2 \%$ (95\% CI $12.6 \%$ to $15.9 \%$ ) in Europe, $14.0 \%$ (95\% CI $11.2 \%$ to $17.1 \%)$ in South America and Caribbean, $14.0 \%$ (95\% CI $9.5 \%$ to $19.1 \%$ ) in North America, and $12.5 \%$ (95\% CI $11.1 \%$ to $13.9 \%$ ) in Australia and New Zealand. After adjusted for mid-year, we identified that the 1-month case fatality in Europe, and South America and Caribbean was significantly higher than Asia ( $R R=1.04,95 \%$ CI 1.00 to $1.06, \mathrm{p}=0.041$; $\mathrm{RR}=1.05,95 \%$ CI 1.01 to $1.09, \mathrm{p}=0.027$, respectively).

There were 17 study periods reporting the genderspecific case fatality of ischaemic stroke. After pooling these study periods, we found that the case fatality was slightly higher in women than in men (for men, $12.1 \%$, $95 \%$ CI $9.6 \%$ to $14.8 \%$; for women, $13.9 \%$, $95 \%$ CI $11.1 \%$ to $16.9 \%$ ), though the difference was not significant $(p=0.365)$. Nine studies with the age-specific case fatality of ischaemic stroke were summarised to estimate the case fatality in different age groups. The case fatality increased with age (online supplementary table 3 ), and the case fatality in patients more than 85 years old $(24.6 \%, 95 \%$ CI $17.7 \%$ to $32.2 \%$ ) was three times higher than in patients less than 64 years old $(6.6 \%, 95 \%$ CI $4.6 \%$ to $8.9 \%$, $\mathrm{p}<0.001)$.

\section{Sensitivity analysis and risk of bias}

When we used the first-ever stroke patients to investigate the sensitivity, it was shown that the worldwide case fatality did not change $(13.3 \%$, 95\% CI $11.9 \%$ to $14.7 \%)$ and the regional differences emerged. The case fatality in North America attenuated to $11.5 \%$ (95\% CI $4.1 \%$ to $21.9 \%$ ) with three time periods, and in other regions, the case fatality was almost unchanged (online supplementary figure 1). Concerning the diagnosis of ischaemic stroke, we summarised the studies with at least $80 \%$ brain

\begin{tabular}{ll}
\hline Table 1 The regional distribution of included study periods \\
\hline Region & Country \\
\hline Asia=11 & China=2; Iran=1; Japan=5; Saudi Arabia=2; Russia=1 \\
Australia and New Zealand=8 & $\begin{array}{l}\text { Australia=7; New Zealand=1 } \\
\text { Europe=43 }\end{array}$ \\
& $\begin{array}{l}\text { Croatia=1; Denmark=1; Estonia=1; Finland=4; France=5; Georgia=1; Germany=1; } \\
\text { Greece=2; } \\
\text { Hungary=1; Ireland=1; Italy=12; Norway=4; Poland=1; Portugal=1; Scotland=1; } \\
\text { Sweden=5; UK=1 }\end{array}$ \\
North America=7 & USA=7 \\
South America and Caribbean=8 & Argentina=1, Brazil=3, Barbados=1, Chile=1, Martinique=2 \\
\hline
\end{tabular}




\begin{tabular}{|c|c|c|c|c|c|c|}
\hline Region & Source & Country & Midyear & $\begin{array}{l}\text { No. of } \\
\text { patients }\end{array}$ & Deaths & Case fatality, $\%(95 \% \mathrm{CI})$ \\
\hline \multirow[t]{44}{*}{ Europe } & Numminen et al, 1996 & Finland & 1973 & 148 & 33 & 22.3 (15.9 to 29.9$)$ \\
\hline & Numminen et al, 1996 & Finland & 1979 & 188 & 46 & $24.5(18.5$ to 31.3$)$ \\
\hline & Bamford et al, 1990 & United Kingdom & 1984 & 545 & 57 & 10.5 (8 to 13.3$)$ \\
\hline & Truelsen et al, 2002 & Denmark & 1985 & 439 & 63 & $14.4(11.2$ to 18$)$ \\
\hline & Béjot et al, 2007 & France & 1987 & 943 & 126 & 13.4 (11.3 to 15.7$)$ \\
\hline & Ricciet al, 1991 & Italy & 1987 & 286 & 28 & $9.8(6.6$ to 13.8$)$ \\
\hline & Immonen-Raiha et al, 1997 & Finland & 1988 & 9074 & 1530 & $16.9(16.1$ to 17.6$)$ \\
\hline & D'Alessandro et al, 2000 & Italy & 1989 & 171 & 21 & $12.3(7.8$ to 18.2$)$ \\
\hline & Hallstrom et al, 2002 & Sweden & 1989 & 1421 & 152 & $10.7(9.1$ to 12.4$)$ \\
\hline & Numminen et al, 2005 & Finland & 1990 & 469 & 91 & $19.4(15.9$ to 23.3$)$ \\
\hline & Khan et al, 1996 & Sweden & 1990 & 5086 & 415 & $8.2(7.4$ to 8.9$)$ \\
\hline & Weissbein et al, 2007 & Poland & 1992 & 407 & 153 & $37.6(32.9$ to 42.5$)$ \\
\hline & Béjot et al, 1994 & France & 1992 & 1043 & 142 & $13.6(11.6$ to 15.8$)$ \\
\hline & Lauria et al, 2003 & Italy & 1993 & 319 & 84 & 26.3 (21.6 to 31.5$)$ \\
\hline & Intiso et al, 1995 & Italy & 1993 & 57 & 14 & $24.6(14.1$ to 37.8$)$ \\
\hline & Intiso et al, 2003 & Italy & 1994 & 60 & 10 & $16.7(8.3$ to 28.5$)$ \\
\hline & Vemmos et al, 1999 & Greece & 1994 & 447 & 119 & $26.6(22.6$ to 31$)$ \\
\hline & Kolominsky-Rabas et al, 1997 & 7 Germany & 1995 & 278 & 32 & $11.5(8$ to 15.9$)$ \\
\hline & Ellekjaer et al, 2003 & Norway & 1995 & 322 & 35 & $10.9(7.7$ to 14.8$)$ \\
\hline & Intiso et al, 1998 & Italy & 1995 & 57 & 8 & $14(6.3$ to 25.8$)$ \\
\hline & Marini et al, 2005 & Italy & 1996 & 3530 & 714 & 20.2 (18.9 to 21.6$)$ \\
\hline & Béjot et al, 2007 & France & 1997 & 909 & 105 & $11.6(9.5$ to 13.8$)$ \\
\hline & D'Alessandro et al, 2000 & Italy & 1997 & 284 & 44 & $15.5(11.5$ to 20.2$)$ \\
\hline & Ovary et al, 2004 & Hungary & 1998 & 4875 & 448 & $9.2(8.4$ to 10$)$ \\
\hline & Vangen-Lonne et al, 2015 & Norway & 1998 & 375 & 36 & $9.6(6.8$ to 13$)$ \\
\hline & Di Carlo et al, 2013 & Italy & 1999 & 234 & 38 & $16.2(11.8$ to 21.6$)$ \\
\hline & Syme et al, 2003 & Scottish & 1999 & 419 & 46 & 11 (8.2 to 14.4$)$ \\
\hline & Correia et al, 2005 & Portugal & 1999 & 554 & 59 & $10.6(8.2$ to 13.5$)$ \\
\hline & Appelros et al, 2002 & Sweden & 2000 & 274 & 27 & $9.9(6.6$ to 14$)$ \\
\hline & Béjot et al, 2007 & France & 2002 & 1045 & 82 & $7.8(6.3$ to 9.6$)$ \\
\hline & Manobianca et al, 2018 & Italy & 2002 & 92 & 10 & $10.9(5.3$ to 19.1$)$ \\
\hline & Tsiskaridze et al, 2004 & Georgia & 2004 & 125 & 24 & $19.2(12.9$ to 27.2$)$ \\
\hline & Aked et al, 2018 & Sweden & 2002 & 364 & 31 & $8.5(5.9$ to 11.9$)$ \\
\hline & Vibo et al, 2007 & Estonia & 2002 & 332 & 73 & $22(17.6$ to 26.8$)$ \\
\hline & Vangen-Lonne et al, 2015 & Norway & 2003 & 413 & 33 & $8(5.6$ to 11$)$ \\
\hline & Corso et al, 2013 & Italy & 2006 & 1057 & 114 & $10.8(9$ to 12.8$)$ \\
\hline & Kelly et al, 2012 & Ireland & 2006 & 390 & 64 & 16.4 (12.9 to 20.5$)$ \\
\hline & Pikija et al, 2013 & Croatia & 2008 & 748 & 128 & $17.1(14.5$ to 20$)$ \\
\hline & Janes et al, 2012 & Italy & 2008 & 506 & 85 & 16.8 (13.6 to 20.3$)$ \\
\hline & Vangen-Lonne et al, 2015 & Norway & 2008 & 367 & 34 & $9.3(6.5$ to 12.7$)$ \\
\hline & Béjot et al, 2013 & France & 2009 & 1092 & 95 & $8.7(7.1$ to 10.5$)$ \\
\hline & Tsivgoulis et al, 2018 & Greece & 2012 & 568 & 92 & $16.2(13.3$ to 19.5$)$ \\
\hline & Aked et al, 2018 & Sweden & 2016 & 334 & 29 & $8.7(5.9$ to 12.2$)$ \\
\hline & Total: $I^{2}=95.2 \%$ & & & 40647 & 5570 & $14.2(12.6$ to 15.9$)$ \\
\hline
\end{tabular}

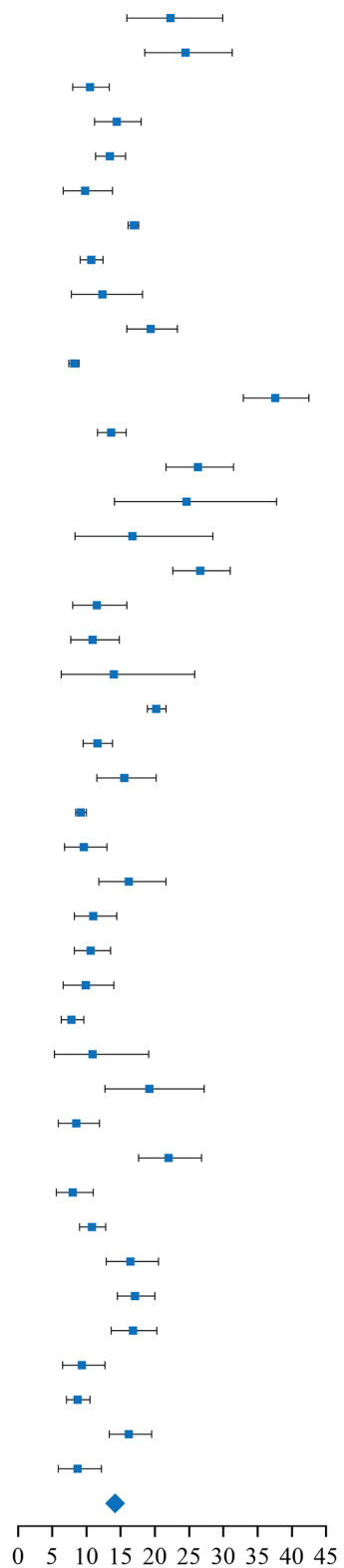

Figure 2 One-month case fatality of ischaemic stroke by region in Europe.

scanning. The overall case fatality was almost unchanged $(13.3 \%, 95 \%$ CI $11.9 \%$ to $14.8 \%)$. Still, Asia had the lowest 1 -month case fatality $(9.7 \%, 95 \%$ CI $7.4 \%$ to $12.2 \%)$. The case fatality in other regions was not significantly changed (online supplementary figure 2). We did not find the potential publication bias through the result of Egger linear regression $(\mathrm{p}=0.208)$.

\section{Temporal trend of 1-month case fatality of ischaemic stroke}

Although the overall temporal trend of the 1-month case fatality was not significant over nearly six decades $(-0.1 \%$ per year, $95 \% \mathrm{CI}-0.2 \%$ to $0.05 \%$, $\mathrm{p}=0.063$ ), we found a regional variation of the temporal trend. Figure 4 shows the temporal trends of 1-month case fatality in different regions. The case fatality in Europe, South America and
North America, and Caribbean decreased during the study periods, while in Australia, New Zealand and Asia the case fatality increased. The case fatality decreased by $0.2 \%$ (95\% CI $0.01 \%$ to $0.4 \%$ ) per year in Europe from 1973 to 2016 , and $0.2 \%$ (95\% CI $0.04 \%$ to $0.4 \%$ ) in North America from 1982 to 2003 . However, the case fatality increased by $0.2 \%$ (95\% CI $0.1 \%$ to $0.4 \%$ ) per year in Australia and New Zealand from 1986 to 2010. The case fatality was not significantly changed in South America and Caribbean $(-0.4 \%, 95 \%$ CI $-0.9 \%$ to $0.2 \%, \mathrm{p}=0.167)$ from 1999 to 2014, and Asia $(0.1 \%, 95 \%$ CI $-0.1 \%$ to $0.4 \%, \mathrm{p}=0.396$ ) from 1990 to 2011 (table 2). There were six study periods from Japan in the region of Asia. When confined the region within Japan, we identified a $0.1 \%$ 


\begin{tabular}{|c|c|c|c|c|c|c|c|}
\hline Region & Source & Country & Midye ar & $\begin{array}{c}\text { No. of } \\
\text { patient }\end{array}$ & Deaths & $\begin{array}{c}\text { Case fatality, \% } \\
\text { (95\%CI) }\end{array}$ & \\
\hline \multirow[t]{12}{*}{ Asia } & Kimura et al, 1998 & Japan & 1990 & 1872 & 107 & $5.7(4.7$ to 6.9$)$ & $H$ \\
\hline & Kita et al, 1999 & Japan & 1991 & 262 & 28 & $10.7(7.2$ to 15.1$)$ & $\longmapsto$ \\
\hline & al-Rajeh et al, 1998 & Saudi Arabia & 1991 & 339 & 34 & $10.0(7.0$ to 13.7$)$ & $\longmapsto$ \\
\hline & Feigin et al, 1995 & Russia & 1992 & 321 & 52 & $16.2(12.3$ to 20.7$)$ & $\longmapsto$ \\
\hline & Kiyohara et al, 2003 & Japan & 1992 & 244 & 22 & $9.0(5.7$ to 13.3$)$ & $\longmapsto$ \\
\hline & Hamad et al, 2001 & Saudi Arabia & 1997 & 173 & 21 & $12.1(7.7$ to 18.0$)$ & $\longmapsto$ \\
\hline & Ovary et al, 2004 & Japan & 1998 & 1843 & 136 & $7.4(6.2$ to 8.7$)$ & -1 \\
\hline & Fang et al, 2004 & China & 2006 & 1184 & 123 & $10.4(8.7$ to 12.3$)$ & $\mapsto$ \\
\hline & Zhang et al, 2003 & China & 2006 & 869 & 147 & $16.9(14.5$ to 19.6$)$ & $\mapsto$ \\
\hline & Shoeibi et al, 2015 & Iran & 2007 & 530 & 94 & 17.7 (14.6 to 21.3$)$ & $\longmapsto$ \\
\hline & Takashima et al, 2017 & Japan & 2011 & 1948 & 151 & $7.8(6.6$ to 9.0$)$ & 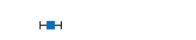 \\
\hline & Total: $I^{2}=93.4 \%$ & & & 9585 & 915 & $10.8(8.3$ to 13.5$)$ & $\bullet$ \\
\hline \multirow{9}{*}{$\begin{array}{c}\text { Aus tralia } \\
\text { and New } \\
\text { Zealand }\end{array}$} & Ward et al, 1988 & Australia & 1986 & 94 & 12 & $12.8(6.8$ to 21.2$)$ & $\longmapsto$ \\
\hline & Islam et al, 2008 & Australia & 1990 & 173 & 15 & $8.7(4.9$ to 13.9$)$ & $\longmapsto$ \\
\hline & Anderson et al, 1997 & New Zealand & 1991 & 376 & 45 & $12.0(8.9$ to 15.7$)$ & $\longmapsto$ \\
\hline & Islam et al, 2008 & Australia & 1996 & 166 & 24 & $14.5(9.5$ to 20.7$)$ & $\longmapsto$ \\
\hline & Thrift et al, 2001 & Australia & 1997 & 200 & 24 & $12.0(7.8$ to 17.3$)$ & $\longmapsto$ \\
\hline & Thrift et al, 2009 & Australia & 1998 & 716 & 86 & $12.0(9.7$ to 14.6$)$ & $\longmapsto$ \\
\hline & Islam et al, 2008 & Australia & 2001 & 138 & 19 & $13.8(8.5$ to 20.7$)$ & $\longmapsto$ \\
\hline & Leyden et al, 2013 & Australia & 2010 & 258 & 41 & $15.9(11.7$ to 20.9$)$ & $\longmapsto$ \\
\hline & Total: $I^{2}=0 \%$ & & & 2121 & 266 & 12.5 (11.1 to 13.9) & $\bullet$ \\
\hline \multirow{8}{*}{$\begin{array}{c}\text { North } \\
\text { America }\end{array}$} & Brown et al, 1996 & USA & 1955 & 276 & 50 & 18.1 (13.8 to 23.2$)$ & $\longmapsto$ \\
\hline & Sacco et al, 1982 & USA & 1962 & 286 & 43 & $15.0(11.1$ to 19.7$)$ & $\longmapsto$ \\
\hline & Brown et al, 1996 & USA & 1965 & 513 & 96 & $18.7(15.4$ to 22.4$)$ & $\longmapsto$ \\
\hline & Brown et al, 1996 & USA & 1975 & 553 & 72 & $13.0(10.3$ to 16.1$)$ & $\longmapsto$ \\
\hline & Brown et al, 1996 & USA & 1985 & 781 & 114 & $14.6(12.2$ to 17.3$)$ & $\mapsto$ \\
\hline & Vernino et al, 2003 & USA & 1987 & 444 & 74 & $16.7(13.3$ to 20.5$)$ & $\longmapsto$ \\
\hline & Hartmann et al, 2001 & USA & 1994 & 980 & 47 & $4.8(3.5$ to 6.3$)$ & \multirow[t]{2}{*}{$\mapsto=1$} \\
\hline & Total: $I^{2}=94.6 \%$ & & & 3833 & 496 & $14.0(9.5$ to 19.1$)$ & \\
\hline \multirow{10}{*}{$\begin{array}{c}\text { South } \\
\text { America } \\
\text { and } \\
\text { Caribbean }\end{array}$} & Olindo, 2014 & Martinique & 1999 & 463 & 55 & $11.9(9.1$ to 15.2$)$ & $\longmapsto$ \\
\hline & Corbin et al, 2004 & Barbados & 2001 & 276 & 64 & 23.2 (18.3 to 28.6$)$ & \\
\hline & Lavados et al, 2005 & Chile & 2001 & 185 & 33 & $17.8(12.6$ to 24.1$)$ & $\longmapsto$ \\
\hline & Minelli et al, 2007 & Brazil & 2004 & 69 & 9 & $13.0(6.1$ to 23.3$)$ & $\Longrightarrow$ \\
\hline & Cabral et al, 2009 & Brazil & 2006 & 610 & 86 & 14.1 (11.4 to 17.1$)$ & $\longmapsto$ \\
\hline & Goulart et al, 2012 & Brazil & 2007 & 365 & 41 & $11.2(8.2$ to 14.9$)$ & $\longmapsto$ \\
\hline & Olindo, 2014 & Martinique & 2012 & 439 & 40 & $9.1(6.6$ to 12.2$)$ & $\mapsto$ \\
\hline & Bahit et al, 2016 & Argentina & 2014 & 251 & 37 & $14.7(10.6$ to 19.7$)$ & $\longmapsto$ \\
\hline & Total: $I^{2}=78.2 \%$ & & & 2658 & 368 & $14.0(11.2$ to 17.1$)$ & $\bullet$ \\
\hline & Overall (including Eu & e): $I^{2}=94$ & & 58301 & 7558 & 13.5 (12.3 to 14.7$)$ & $>$ \\
\hline
\end{tabular}

One-month case fatality of ischemic stroke (\%)

Figure 3 One-month case fatality of ischaemic stroke by region.

(95\% CI $-0.1 \%$ to $0.3 \%$ ) annual decline in 1-month case fatality.

\section{Sensitivity analysis of temporal trend}

The sensitivity analysis revealed an overall decrease of $0.1 \%$ (95\% CI $0.04 \%$ to $0.3 \%$ ) in study periods with firstever stroke and $0.1 \%$ (95\% CI $-0.1 \%$ to $0.3 \%$ ) in study periods with at least $80 \%$ brain scanning. The corresponding changes of case fatality in different regions were list in online supplementary table 4 .

\section{DISCUSSION}

This meta-analysis, including 77 study periods with 58301 patients after ischaemic stroke from 30 countries, indicated that the 1-month case fatality of ischaemic stroke and its temporal trend were divergent across different geographical regions. Overall, the 1-month case fatality was $13.5 \%$ (95\% CI $12.3 \%$ to $14.7 \%$ ), without obvious sex difference. Though globally the case fatality rate did not significantly decline over a period spanning nearly six decades, it was estimated that the case fatality decreased significantly by $0.2 \%$ ( $95 \%$ CI $0.01 \%$ to $0.4 \%$ ) per year in Europe and by $0.2 \%$ (95\% CI $0.04 \%$ to $0.4 \%$ ) in North America.

Previous studies have deeply explored the disparity in stroke mortality between blacks and whites, ${ }^{9-11}$ while the difference between white and Asian or other ethnic has not been studied in depth. In our study, it was found that the 1-month case fatality of ischaemic stroke patients in Asia was significantly lower than in Europe and in South America and Caribbean. A multicentre study including the young patients with first-ever acute stroke (18 to 45 years of age) showed that blacks and whites had about threefold higher risk of 1-month case fatality than 


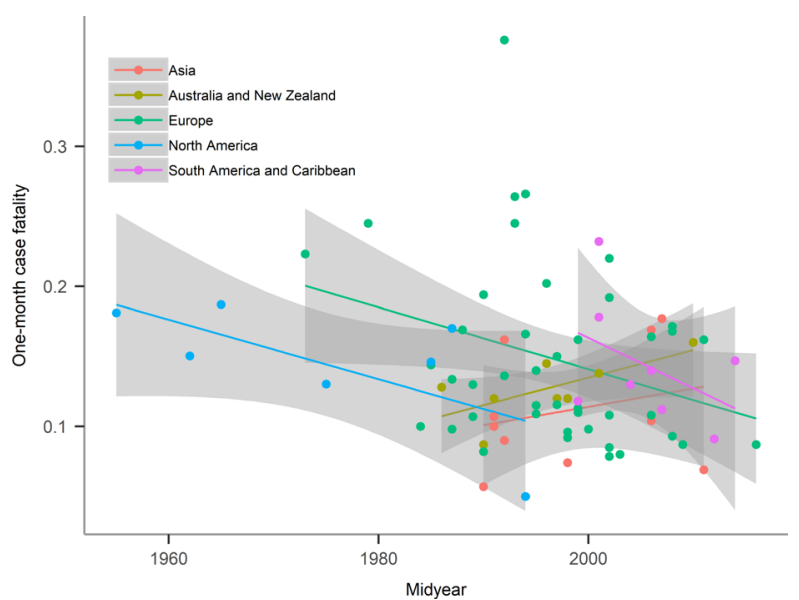

Figure 4 The temporal trend of 1-month case fatality after ischaemic stroke by region. The solid circles with different colours indicate the 1-month case fatality after ischaemic stroke in different regions. The lines with different colours indicate the estimated linear trends of the 1-month case fatality after ischaemic stroke over time. The shaded area represents the $95 \% \mathrm{Cl}$ for the 1-month case fatality after ischaemic stroke.

Asians. ${ }^{12}$ This result was consistent with the finding in our present study, though the patient was young and stroke subtype was not specified. The study from New Zealand showed that the crude 1-month case fatality of ischaemic stroke was lower in Asian people compared with Europeans, Pacific and Māori people. ${ }^{13}$ When adjusted for age and sex, the case fatality was still lower for Asians in comparison with Europeans and the ratio was $0.71(95 \%$ CI 0.54 to 0.92 ) between 2000 and 2004. However, the sample sizes in these studies were small and this disparity needs to be further corroborated by comparison between regions or ethnic groups. There are some possible explanations for this phenomenon. In terms of the ischaemic stroke aetiology, Asians had a lower proportion of cardioembolism than whites $(8.1 \%$ vs $19.7 \%)$, who featured a higher risk of long-term mortality. ${ }^{14} 15$ On the contrary, Asians had a higher proportion of small vessel occlusion, characterised by a lower 30-day case fatality rate. ${ }^{16}{ }^{17}$ Age

Table 2 Annual percentage change of 1-month case fatality after ischaemic stroke according to geographical region

\begin{tabular}{|c|c|c|c|}
\hline Region & $\begin{array}{l}\text { Number } \\
\text { of study } \\
\text { periods }\end{array}$ & $\begin{array}{l}\text { Annual change, \% } \\
(95 \% \mathrm{CI})\end{array}$ & $P$ value \\
\hline Overall & 77 & $-0.1(-0.2$ to 0.05$)$ & 0.063 \\
\hline Asia & 11 & $0.1(-0.1$ to 0.4$)$ & 0.396 \\
\hline $\begin{array}{l}\text { Australia and } \\
\text { New Zealand }\end{array}$ & 8 & $0.2(0.1$ to 0.4$)$ & 0.010 \\
\hline Europe & 43 & $-0.2(-0.4$ to -0.01$)$ & 0.037 \\
\hline North America & 7 & $-0.2(-0.4$ to -0.04$)$ & 0.018 \\
\hline $\begin{array}{l}\text { South America } \\
\text { and Caribbean }\end{array}$ & 8 & $-0.4(-0.9$ to 0.2$)$ & 0.167 \\
\hline
\end{tabular}

was an important risk factor to predict the 1-month case fatality of ischaemic stroke. ${ }^{18} 19$ It was suggested that in some Asian countries the mean age of stroke onset was almost 10 years younger compared with Western countries. ${ }^{20}{ }^{21}$ Moreover, the prevalence of risk factors, such as smoking, alcohol intake and atrial fibrillation, was lower in Asian, which might contribute to favourable outcomes after stroke. ${ }^{16}$ In light of the regional difference, when the 1-month case fatality of ischaemic stroke was used as an endpoint in a worldwide multicentre clinical trial, the sample size in regions or countries should be estimated individually.

Globally, the mortality rate of ischaemic stroke has been declining, from 71.3 per 100000 in 1990 to 57.3 per 100000 in $2013{ }^{6}{ }^{6}$ This decline can be attributed to the decrease of incidence of stroke and lower case fatality rate. ${ }^{22}$ It was estimated that the incidence of ischaemic stroke per 100000 persons had declined from 113.3 in 1990 to 98.9 in 2013 for females and 147.4 in 1990 to 132.77 in 2013 for males. ${ }^{23}$ It mainly resulted from cardiovascular risk control, such as treatment of hypertension, diabetes and dyslipidaemia, and smoking cessation programmes, which improved overall people's health. ${ }^{22}$ On the other hand, lower case fatality can lead to declining mortality. In our present analysis, we observed a non-significant decrease of annual $0.1 \%$ in the 1-month case fatality of ischaemic stroke. The ideal method to examine the temporal trend of case fatality is to observe in one region over a long time using the standardised definition and method of data collection. ${ }^{1}$ Ten studies included in this analysis reported at least two time periods. Some studies ${ }^{24-30}$ suggested the case fatality was stable, while some ${ }^{31-33}$ suggested it had decreased. The temporal trends of case fatality after stroke may be different between men and women. Data from the Framingham Study suggested that the 30-day case fatality of stroke declined significantly from $23 \%$ to $14 \%$ within about 50 years for men (annually decreased by $0.2 \%$ ), but not significantly for women (from $21 \%$ to 20\%). ${ }^{34}$ However, it did not detail the changes of case fatality in ischaemic stroke. Similarly, a study in a Norwegian municipality revealed the 1-month case fatality of ischaemic stroke decreased significantly in men from 1995 to 2010 , but not in women. ${ }^{26}$ Additionally, the temporal trend may vary for different subtypes of ischaemic stroke. A population-based registry in France revealed that the 28-day case fatality decreased significantly for the type of lacunar infarct, but this was not observed in other types of ischaemic stroke. ${ }^{31}$ Geographical region is another factor that may cause divergent temporal trends of case fatality. We found that except for Europe and North America, other regions did not see a significant decline in case fatality. This can be partly explained by a small number of studies in other regions. The decline of case fatality of ischaemic stroke mainly contributed to mild strokes. This resulted from beneficial changes in risk factors ${ }^{32}$ and the improvement in stroke care, such as the door-to-needle time, endovascular stroke therapy and comprehensive stroke units. ${ }^{35-37}$ We should note that as the changes 
in case fatality over time was minor and the number of included study periods relatively small for each region, the results should be explained with caution.

To our knowledge, this is the largest study that summarises the population-based studies to estimate the 1-month case fatality of ischaemic stroke and investigate its temporal trend. There are several limitations that should be noted. First, we cannot adjust for stroke severity, as well as vascular risk factors and other potential risk confounders due to lack of data on confounding factors. Future research controlling the impact of the potential risk factors may be warranted. In addition, this study is a systematic review and meta-analysis, rather than a large epidemiological study. We observed a high heterogeneity between studies in the meta-analysis. It may be partly explained by different characteristics of populations and the method of case identification. In this analysis, we set strict inclusion and exclusion criteria to ensure that the study can provide reliable case fatality of ischaemic stroke and the methodology was comparable. Furthermore, compared with Europe, studies in other regions were relatively limited, such as in Africa. Finally, we may have missed some 'grey zone' literature. In order to reduce this bias, we searched literature by hand and conducted sensitivity analysis.

Case fatality is an important epidemiological metric. The magnitude of case fatality represents the severity of certain diseases and the temporal trend of case fatality can be an indicator of the changes in stroke management and characteristics of patients. In the future, it is necessary to observe case fatality after ischaemic stroke in a representative population over a long period, especially in countries without data to date. Since the subtypes of ischaemic stroke are associated with the outcome, ${ }^{38}$ we should also contrive to evaluate the case fatality or incidence according to the subtypes of ischaemic stroke. Moreover, a substantial number of poststroke patients survive with long-term disability; so, the morbidity after stroke should be further studied to improve the prognosis. In addition to stroke mortality and morbidity, the focus should also be on the preventive strategy to decrease the incidence so that stroke burden can ultimately be reduced.

\section{CONCLUSION}

In conclusion, the 1-month case fatality of ischaemic stroke and its temporal trend vary across different countries or regions. More studies should address the reason for the decrease, which would contribute to reducing the regional difference.

Contributors RZ: study selection, data extraction, methodology and writing original draft preparation. YW: study selection and data extraction. MY: data analysis. JF: methodology and revision of the manuscript. YW: conceptualisation, supervision and funding acquisition. GL: conceptualisation, methodology, revision of the manuscript and funding acquisition.

Funding This study was supported by the Ministry of Science and Technology of the People's Republic of China (2017YFC1307702), Capital's Funds for Health Improvement and Research (2020-1-2041) and Beijing Municipal Administration of Hospitals' Sail Plan (XMLX201712).
Competing interests None declared.

Patient consent for publication Not required.

Provenance and peer review Not commissioned; externally peer reviewed. Data availability statement All data relevant to the study are included in the article or uploaded as supplementary information. You can obtain related data from the published articles.

Open access This is an open access article distributed in accordance with the Creative Commons Attribution Non Commercial (CC BY-NC 4.0) license, which permits others to distribute, remix, adapt, build upon this work non-commercially, and license their derivative works on different terms, provided the original work is properly cited, appropriate credit is given, any changes made indicated, and the use is non-commercial. See: http://creativecommons.org/licenses/by-nc/4.0/.

ORCID iDs

Runhua Zhang http://orcid.org/0000-0003-4825-191X

Yongjun Wang http://orcid.org/0000-0002-9976-2341

Gaifen Liu http://orcid.org/0000-0002-7038-3444

\section{REFERENCES}

1 Nieuwkamp DJ, Setz LE, Algra A, et al. Changes in case fatality of aneurysmal subarachnoid haemorrhage over time, according to age, sex, and region: a meta-analysis. Lancet Neurol 2009;8:635-42.

2 Sacco RL, Wolf PA, Kannel WB, et al. Survival and recurrence following stroke. The Framingham study. Stroke 1982;13:290-5.

3 Stroke Unit Trialists' Collaboration. Organised inpatient (stroke unit) care for stroke. Cochrane Database Syst Rev 2013:CD000197.

4 Prabhakaran S, Ruff I, Bernstein RA. Acute stroke intervention: a systematic review. JAMA 2015;313:1451-62.

5 GBD 2015 Mortality and Causes of Death Collaborators. Global, regional, and national life expectancy, all-cause mortality, and causespecific mortality for 249 causes of death, 1980-2015: a systematic analysis for the global burden of disease study 2015. Lancet 2016;388:1459-544.

6 Feigin VL, Krishnamurthi RV, Parmar P, et al. Update on the global burden of ischemic and hemorrhagic stroke in 1990-2013: the GBD 2013 study. Neuroepidemiology 2015;45:161-76.

7 van Asch CJ, Luitse MJ, Rinkel GJ, et al. Incidence, case fatality, and functional outcome of intracerebral haemorrhage over time, according to age, sex, and ethnic origin: a systematic review and meta-analysis. Lancet Neurol 2010;9:167-76.

8 Wells GA, Shea B, O'Connell D, et al. The Newcastle-Ottawa scale (NOS) for assessing the quality of nonrandomised studies in meta-analyses. Available: http://www.ohri.ca/programs/clinical_ epidemiology/oxford.asp [Accessed 10 Jan 2019].

9 Gardener H, Leifheit EC, Lichtman JH, et al. Racial/Ethnic Disparities in Mortality Among Medicare Beneficiaries in the FL - PR CR eSD Study. J Am Heart Assoc 2019;8:e009649.

10 Howard G, Moy CS, Howard VJ, et al. Where to focus efforts to reduce the Black-White disparity in stroke mortality: incidence versus case fatality? Stroke 2016;47:1893-8.

11 Kissela B, Schneider A, Kleindorfer D, et al. Stroke in a biracial population: the excess burden of stroke among blacks. Stroke 2004;35:426-31.

12 Tsivgoulis G, Putaala J, Sharma VK, et al. Racial disparities in early mortality in 1,134 young patients with acute stroke. Neurol Sci 2014;35:1041-9.

13 Sandiford P, Selak V, Ghafel M. Are ethnic inequalities in 30-day ischaemic stroke survival emerging as treatment becomes more effective? N Z Med J 2016;129:8-14

14 Gezmu T, Schneider D, Demissie K, et al. Risk factors for acute stroke among South Asians compared to other racial/ethnic groups. PLoS One 2014;9:e108901.

15 Petty GW, Brown RD, Whisnant JP, et al. Ischemic stroke subtypes : a population-based study of functional outcome, survival, and recurrence. Stroke 2000;31:1062-8.

16 Sen S, Dahlberg K, Case A, et al. Racial-ethnic differences in stroke risk factors and subtypes: results of a prospective hospital-based registry. Int J Neurosci 2013;123:568-74.

17 de Jong G, van Raak L, Kessels F, et al. Stroke subtype and mortality. A follow-up study in 998 patients with a first cerebral infarct. J Clin Epidemiol 2003;56:262-8.

18 Saposnik G, Kapral MK, Liu Y, et al. IScore: a risk score to predict death early after hospitalization for an acute ischemic stroke. Circulation 2011:123:739-49.

19 O'Donnell MJ, Fang J, D'Uva C, et al. The plan score: a bedside prediction rule for death and severe disability following acute ischemic stroke. Arch Intern Med 2012;172:1548-56. 
20 Mehndiratta MM, Khan M, Mehndiratta P, et al. Stroke in Asia: geographical variations and temporal trends. J Neurol Neurosurg Psychiatry 2014;85:1308-12.

21 Wasay M, Khatri IA, Kaul S. Stroke in South Asian countries. Nat Rev Neurol 2014;10:135-43.

22 Lackland DT, Roccella EJ, Deutsch AF, et al. Factors influencing the decline in stroke mortality: a statement from the American heart Association/American stroke association. Stroke 2014;45:315-53.

23 Barker-Collo S, Bennett DA, Krishnamurthi RV, et al. Sex differences in stroke incidence, prevalence, mortality and Disability-Adjusted life years: results from the global burden of disease study 2013. Neuroepidemiology 2015;45:203-14.

24 Numminen $\mathrm{H}$, Kotila M, Waltimo O, et al. Declining incidence and mortality rates of stroke in Finland from 1972 to 1991. Results of three population-based stroke registers. Stroke 1996;27:1487-91.

25 D'Alessandro G, Bottacchi E, Di Giovanni M, et al. Temporal trends of stroke in Valle d'Aosta, Italy. incidence and 30-day fatality rates. Neurol Sci 2000;21:13-18.

26 Vangen-Lønne AM, Wilsgaard T, Johnsen SH, et al. Time trends in incidence and case fatality of ischemic stroke: the Troms $\varnothing$ study 1977-2010. Stroke 2015;46:1173-9.

27 Aked J, Delavaran H, Norrving B, et al. Temporal trends of stroke epidemiology in southern Sweden: a population-based study on stroke incidence and early case-fatality. Neuroepidemiology 2018;50:174-82.

28 Islam MS, Anderson CS, Hankey GJ, et al. Trends in incidence and outcome of stroke in Perth, Western Australia during 1989 to 2001: the Perth community stroke study. Stroke 2008;39:776-82.

29 Brown RD, Whisnant JP, Sicks JD, et al. Stroke incidence, prevalence, and survival: secular trends in Rochester, Minnesota, through 1989. Stroke 1996;27:373-80.
30 Hartmann A, Rundek T, Mast H, et al. Mortality and causes of death after first ischemic stroke: the Northern Manhattan stroke study. Neurology 2001;57:2000-5.

31 Bejot Y, Rouaud O, Durier J, et al. Decrease in the stroke case fatality rates in a French population-based twenty-year study. A comparison between men and women. Cerebrovasc Dis 2007;24:439-44.

32 Immonen-Räihä $\mathrm{P}$, Mähönen M, Tuomilehto J, et al. Trends in case-fatality of stroke in Finland during 1983 to 1992. Stroke 1997;28:2493-9.

33 Intiso D, Stampatore P, Zarrelli MM, et al. Incidence of first-ever ischemic and hemorrhagic stroke in a well-defined community of southern Italy, 1993-1995. Eur J Neurol 2003;10:559-65.

34 Carandang R, Seshadri S, Beiser A, et al. Trends in incidence, lifetime risk, severity, and 30-day mortality of stroke over the past 50 years. JAMA 2006;296:2939-46.

35 Tong X, Wiltz JL, George MG, et al. A decade of improvement in Door-to-Needle time among acute ischemic stroke patients, 2008 to 2017. Circ Cardiovasc Qual Outcomes 2018;11:e004981.

36 Saber H, Navi BB, Grotta JC, et al. Real-World treatment trends in endovascular stroke therapy. Stroke 2019;50:683-9.

37 Pross C, Berger E, Siegel M, et al. Stroke units, certification, and outcomes in German hospitals: a longitudinal study of patientbased 30-day mortality for 2006-2014. BMC Health Serv Res 2018;18:880.

38 Kolominsky-Rabas PL, Weber M, Gefeller O, et al. Epidemiology of ischemic stroke subtypes according to TOAST criteria: incidence, recurrence, and long-term survival in ischemic stroke subtypes: a population-based study. Stroke 2001;32:2735-40.

39 Arsava EM, Helenius J, Avery R, et al. Assessment of the predictive validity of etiologic stroke classification. JAMA Neurol 2017;74:419-26. 